\title{
Assessment of China's 1985-2017 Higher Education Policy Reform: Nation-Building Directives
}

\author{
L. Steynberg, J. P. Grundling, B. Liu, and Y. Li
}

\begin{abstract}
The Chinese Dream presented by president $\mathrm{Xi}$ Jinping focused on the renewal of the Chinese nation, the prosperity of the country and the well-being of its people. Incorporating the global influence ambition of China into nation-building and education, this study employed a macro policy analysis approach to synthesize the effects of the state-led ideals on nation-building and the roles to be played by higher education. A total of nine comprehensive policies, covering the period 1985 to 2017 , and receptive to globalization, nation-building and higher education were selected. The findings revealed that nation-building in the post-Moa era is built upon three critical priority determinants labelled global influence, socialist market economy and talent management. These core nation-building determinants delineate specific higher education guidelines in terms of citizen education, science and technology, talent management, and innovation amidst accelerating global modernization and freedom-of-mind requirement for the establishment of a socialist consultative democracy. The findings further offer direction to higher education for the provision of a fit-for-purpose workforce capable of operating in both a modern global and local market.
\end{abstract}

Index Terms-Higher education, nation building, policy analysis, rejuvenation.

\section{INTRODUCTION}

China's ambition of rejuvenation is based upon the assertions of building the nation and being an influential member of the "Great Power Relations" group to regain its formal international status, accomplish economic prosperity, restore fair international relationships and assist in solving global problems [1], [2]. President Xi Jinping clearly signified the preceding during his visit to the United States of America shortly before the 2012 G7 summit where he proposed a new type of "Great Power" to solve global problems and create a favorable international environment for China's domestic rejuvenation [3]. A critical dimension

Manuscript received January 1, 2020; revised October 12, 2020. This work was supported in part by Hebei University of Technology, Tshwane University of Technology and the Higher Educational Reform Fund of Hebei Province, People's Republic of China Grant 2017GJJG022.

L. Steynberg is with the School of Economics and Management, Hebei University of Technology, Tianjin, China. She is also with the Department of Management and Entrepreneurship, Tshwane University of Technology, Pretoria, South Africa (e-mail: steynbergl@tut.ac.za).

J. P. Grundling is with the Department of Management and Entrepreneurship, Tshwane University of Technology, Pretoria, South Africa (e-mail: grundlingjp@tut.ac.za).

B. Liu is with the Department of Economics and Management, Hebei University of Technology, Tianjin, China (e-mail: liubing@hebut.edu.cn).

$\mathrm{Y}$. $\mathrm{Li}$ is with the School of Economics and Management, Hebei University of Technology, Tianjin, China (e-mail: yuan.li@ hebut.edu.cn). of domestic rejuvenation relates to nation-building. [2] stated that the Chinese Dream is about the great renewal of the Chinese nation, the prosperity of the country, the rejuvenation of the nation, and the well-being of its people. To accomplish this, Chinese leaders consider education as foundational and instrumental in national rejuvenation [4].

Taking into account that both "nation-building" and "education" are by nature multi-dimensional and multi-variate, it could be assumed that the influence of education on "nation-building" may result in a wide range of possible local, regional and international contrasts vis-à-vis historical, political, economic, cultural and other contextual factors and drives to develop higher education [5]-[9]. Examples of the influence of higher education may typically include differences in the provision of educational services relating to science and technology, the innovation drive [10], human resource development, geographic priorities and education's role in nation-building. Evaluating the global influence ambition of China within nation-building and education, necessitates a macro-analysis approach that can be regarded as rational in nature. For this reason, a sample of nine milestone policies were selected, as these policies have substantially affected the discourse of nation-building and higher education in China, are comprehensive in nature, and receptive to internationalisation. These policies covered the timeframe 1985 to 2017.

The analysis intends to indicate how higher education contributes through teaching, research and service to China's nation-building ambition whilst simultaneously supporting the global influence ambition of the country. By adopting a policy-analysis approach, the researchers attempted to avoid the possibility of applying outdated theoretical approaches as warned by [11] to describe, interpret and suggest development discourses in a mostly under-researched area [12]. The research is regarded as critical for higher education to remain relevant in the context of both the global and domestic environment because the outcomes produced by higher education should be positive, contain reciprocal benefit to all concerned, and encourage common values [13], [14]. To achieve these outcomes in the current global and networked international competitive environment is not only challenging but requires strategic responses to initiate accelerated development and changes in the higher education system to realize nation-building ambitions. According to scholars, such as [15]-[17], nation-building would require quality improvement of higher education, scholarship, knowledge development, talent recruitment, workforce development, international positioning and international citizenship, and providing greater value to the constituencies of higher education institutions as priorities in higher 
education.

Higher education institutions can use the findings to improve their assessment to better assess the relative importance of the influencing factors contained in the policy instruments relevant to nation-building in China. Despite the importance of policy intentions, limited research has systematically identified, using a structured coding process, to explain the key factors that underline nation-building within a socialist model with Chinese characteristics and that could be addressed by higher education. The research is designed to fill this gap.

This paper is organized as follows. In the first section, the importance of policy analysis relating to higher education and its impact on nation-building in China is discussed. It is followed by the research methodology and design. The findings are then presented and discussed. The paper concludes with practical implications of the study.

\section{POLICY ANALYSIS AND THE IMPACT OF HigHER EDUCATION ON NATION-BUILDING}

Policy analysis can be regarded as a social science initiative focusing on the ideation factor in the behavior of the state trying, through decision making, to weave together domestic concerns and ambitions with the international and global concerns and ambitions of the state [18]. As such, it represents a macro-level analysis that allows researchers to organize and present findings located close to the determinants of actions enclosed by a core group of officials who act on behalf of the political society [19]. In this study, the focus is on policy analysis of higher education in China as it impacts on nation-building. [11] defines nation-building as "any activity, planned or not, that increases the degree of commonality in lived, experienced and communicative practice among people living in a particular country, especially those that simultaneously help to bridge local differences and to distinguish citizens of one country from those of another, but also including those that increase commonality across both the country and the globe". In brief, the aim is to consolidate the bond between the individual and the homeland [20].

Higher education is one of the activities that occupy a core position in nation-building. In turn, nation-building may have an exemplary effect on the higher education system by suggestion models that can serve as ideals, such as promoting a preferred form of moral education in which morality, politics and ideology are intertwined [11]. Also, citizenship education, a keystone of nation-building, often serves as a state instrument for political socialization, creating a sense of collective membership, promoting a sense of rights and responsibilities, and equipping the populace with required literacy, skills, attitudes and competencies to become functional and responsible citizens in a given environment [21]. In the United Stated and England, students are encouraged to develop a global outlook whilst also stressing the importance of learning about national and local institutions, cultures and traditions, and how these relate to other countries [22], [23]. According to [12], the post-Mao China attempted to foster a national identity and a modern citizenry using pragmatic market forces to revive its socialist economy and building traditional Chinese values to address social transitions caused by globalization. The latter in particular offered the challenge of being politically and ideologically open and accommodative to assist Chinese scholars to develop global and local identities to function as responsible citizens in a multi-levelled, multi-cultural world in a way that will also be acceptable to the Communist Party of China's Central Committee-led state which stressed patriotism and ethic qualities.

In this current era of prosperity and progress, a preference exists for people with experience and talents that could serve as sources of national strength. In China, in general, the state-led development approach has become a national cause, transformation a collective effort involving all territories and people, while a key priority is the cohesion of the nation's people in building socialism with Chinese characteristics and a modernized state with moderate prosperity for all [24].

\section{Research Methodology AND Design}

The following research approach was followed to address the purpose of the research that aims to synthesize the effects of the state-led ideals on nation-building and the roles to be played by higher education. Data were collected by means of policy documents related to higher education in the People's Republic of China (PRC). Thematic analysis was applied to identify constructs and cluster analysis was used to assess the similarities and differences of units based on empirical information to provide a description of higher education reform in the PRC.

\section{A. Qualitative Research Tradition}

The research design followed a systematic structural approach. This research is located within the interpretivist paradigm and imbedded in the epistemological belief [25]. Recently, numerous studies relating to higher education and policy analysis have been qualitative in nature [26]-[29]. Furthermore, qualitative research methods are frequently used in the analysis of critical approaches [30]. Qualitative research is a research tradition grounded on exploration, description, analysis and interpretation [31], [32]. Since the main objective of this research was to explore policies of higher education within the Chinese context, the research is situated within the qualitative research paradigm.

\section{B. Sampling}

Theoretical sampling technique is a form of purposive sampling linked to Grounded Theory and sampling continuous during preliminary data collection with the emergence of themes and explanations until data saturation is reached. Sampling in content analysis follows a similar process as in survey research, but as opposed to sampling of people from a population, texts are sampled from a corpora, representing a population of text. Within the context of this research, the corpora allude to all the PRC policy documents on higher education, namely. The sampling units were therefore the corpus, the nine selected higher education policies that were analysed. These higher education policies, were examined from a policy content perspective and organized according to subject classification. During the 
qualitative analysis, particular consideration was given to the exploratory and descriptive nature of the policies on higher education.

\section{Content Analysis as Data Source}

Content analysis, as a conventional qualitative research analysis [33]-[35], was used to determine the factors in the various reform phases of China's higher education. The official policy documents, which specifically refer to higher education in the PRC from 1985 to 2017, were used for content analysis. In the context of this research, the succeeding nine national policies were selected to explore the transformation of higher education in China: the Chinese Communist Party Central Committee (CCP CC) Decision on Educational System Reform of 1985 [36], Outline for Reform and Development of Education in China of 1993 [37], Action Plan for Revitalization of Education in the Twenty-First Century of 1999 [38], 2003-2007 Action Plan for Revitalization of Education of 2003 [39], The Full Implementation of the 2003-2007 Action Plan for Invigorating Education of 2004 [40], The National Outline for Mid- and Long-Term Education Planning and Development of 2010 [41], $13^{\text {th }}$ Five Year Plan for Economic and Social Development of the People's Republic of China of 2016 [42], Implementation Measures to Coordinate Development of World-Class Universities and First-Class Discipline Construction as part of the Thirteen Five Year Plan on Education of 2017 [43], and Secure a Decisive Victory in Building a Moderately Prosperous Society in all Respects and Strive for the Great Success of Socialism with Chinese Characteristics for a New Era of 2017 [44]. These nine macro policies on higher education incorporate both independent national education policies, as well as general higher education policies. These policy documents were further used to gain insight into the research issues [31], as well as to supplement evidence from other sources [45], to ensure that the findings and analysis are substantive and credible. [46] articulates the importance of document analysis in research, and specified that:

1) The document itself forms a field of research and should not merely be seen as a pillar for action;

2) Documents need to be regarded as positioning products, not fixed and stable;

3) Documents are produced in a social setting and are always considered collective (social) products;

4) Determining how documents are used in an organized environment, that is the function of documents, should be an important part of any social scientific research project; and

5) When working with documents as a field of study, the dynamics of the relationship between production, consumption and content should be taken into account.

The nine policies were selected for analysis for a number of reasons. Firstly, these policies are all guideline policies, which substantially affected the discourse and development of education in China. Moreover, they are exhaustive policies vis-à-vis all aspects of education governance. These policies demonstrate the degree to which the government perceives and is receptive to education, which implies the significance of education for the Chinese government. Finally, these policies are transformational policies characterizing education development in different timespans. An examination of these policies issued during the 1980s to 2017 can thus demonstrate the evolving nature of education over nearly four decades.

\section{Data Analysis}

Each of the above policy documents was analysed using the qualitative content analysis technique: upload, coding, classification, identification of main themes, conceptualization and analysis using Qualitative Data Analysis (QDA) software (NVivo 12) [33]-[35]. In accordance with [47], NVivo was used to manage data, because the software is a central repository for all information collected. It furthermore offers an opportunity to rapidly acquire conceptual and theoretical knowledge. Three sequential stages were utilised in the analysis of the data. During Phase I, only the first of the three stages of the grounded theory methodology for data analysis was employed. A full grounded theory approach comprises of a series of precise procedures and techniques to assist the researcher to develop an inductively derived grounded theory about a phenomenon [48] to discover theory from the collected data [49]. To achieve the Phase I, a core category at a high level of abstraction is pursued by using a progressive coding procedure of the collected data [50]. Open-coding, based on the first stage of grounded theory, was used to search for conceptual articulations and substitutes for nation-building in every policy to shape similar concepts into categories or sub-categories with conceptual names allocated to them [48]. Accordingly, theme and pattern recognition were the foci of the research. In the second stage of the research, comparison and differences of the recurrence of the articulations were undertaken and categorized in relation to the characteristics of nation-building. During the last stage, the contexts in which the articulations are used were analyzed to determine the particular objectives of nation-building in China's higher education and the methods for achieving these objectives. Thus, the core categories central to nation-building within the higher education phenomenon emerged.

Following qualitative content analysis, data were analyzed using the phases of qualitative text analysis as proposed by [51]. The qualitative text analysis phases included determining the valuation category; identifying and coding the text relevant to a specific category; compiling code segments of the valuation category on a case-by-case basis; evaluating categories for assigning findings and if necessary, analyzing the definitions and the number of exits; evaluating and coding the entire document; employing simple category-based evaluation; and complex qualitative and quantitative analysis and visualization.

The nine policy documents were imported into NVivo 12 software. Paper and pencil coding as well as open coding were employed to code the data, combined with thematic qualitative text analysis to analyze the data generated in the policy documents in order to create thematic categories. Codes were categorized that shared similarities, and categories were constructed through the inductive approach. Analytic memo writing was used to search for relevant 
information to gain a deeper understanding of nation-building from a higher education policy perspective. Analysis of the policy documents offered evidence of changes implemented in higher education by the PRC.

Three clustering techniques are available in NVivo of which the Jaccard's coefficient was selected for cluster analysis. The Jaccard's coefficient was selected grounded on the purpose of analysis that is descriptive and exploratory in nature, and its accessibility in NVivo. Clusters were generated dependent on the word similarity measured by Jaccard's coefficient and are discussed in the next section.

\section{FINDINGS}

As far as nation-building is concerned three priorities underpin the services that need to be rendered by higher education in China namely, i) global influence (293; 42\%); ii) socialist market economy $(225 ; 33 \%)$; and iii) talent management (172; 25\%) (Fig. 1).

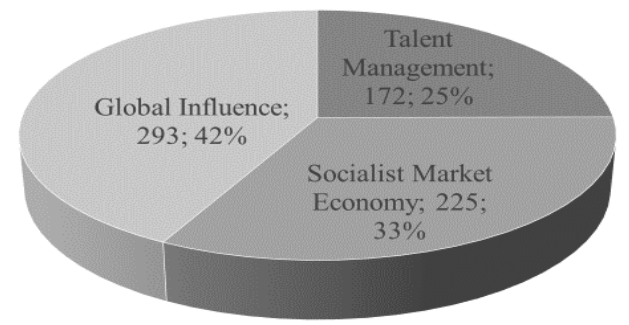

Fig. 1. Nation-building determinants.

\section{A. Global Influence}

\section{1) Strategic strength}

The 1985 policy on higher education, Decision on Education System Reform, had the fundamental purpose of improving the national quality of people. This purpose was based on the premise that limited professional talents, outdated social and economic needs and an inadequate contemporary scientific culture existed. Based on these tripartite limitations, the systematic reform of the education system commenced. Through an amalgamated effort, that is party, society and people of all ethnic groups, the reform of the education system was implemented in order to build a prosperous, strong, democratic and civilized modern socialized country. For this reason, the principle of "training first and then employment" was adopted to ensure proper political, cultural and skill preparation and reformation of the labor force. It was envisaged that by the end of the twentieth century, higher education must provide a well-rounded workforce who are skilled and politically and culturally prepared to offer services equivalent to China's economic strength. It was therefore imperative to align the education enrolment plan with the immediate and long-term needs of the country. Financial resources and respect for the teaching profession were also echoed in the systematic reform of the education system [36].

The $14^{\text {th }}$ National Congress of the Communist Party of China developed a cross-century plan to rejuvenate the country and re-confirm the strategic priority of education in China to realize the goal of socialist modernization. The " 211
Project", launched in 1995, focused on the establishment of a number of world-class higher education institutions and disciplines. This program provided a key platform for the cultivation of innovative talents in China and the construction of the national innovation system. In the strive towards modernization, the need to develop world-class and high-level universities that could operate on advanced levels, and secondly to build a lifelong learning system for the people by making full use of modern information technology, distant education and other educational resources emerged. Despite the greater prominence of modernization in universities the strengthening of traditional, revolutionary, humanities and art education of the Chinese nation was reconfirmed.

In 2003, the 2003-2007 Action Plan for Revitalization of Education [39] was released. Accordingly, the emphasis shifted to the expansion of China's international competitiveness. Various strategies were followed to ensure the advancement of international competitiveness, including the establishment of world-class and high-level universities and disciplines, coordinated expansion and fostering of rapid development, promoting opening-up of higher education to the outside world and strengthening international cooperation and exchanges to comprehensively strengthen higher education in and outside China. To accomplish the preceding, an education brand strategy for China was implemented. In addition, an educational input mechanism was proposed suitable for the socialist market economy system to meet public education demands by contributing to stable and sustainable growth.

The most recent guidance was provided by the Implementation Measures for Promoting World Class Universities and First-Class Discipline Construction [43] policy document of 2017 which emphasized challenges in the economic and social spheres that need to be solved to remain relevant at the global frontier of science and technology developmental levels. These challenges include:

1) Building cross-integration and collaborative innovations to bolster social benefits and international influence;

2) Emphasize innovations in environmental protection and public wellbeing including housing, healthcare and elderly care, and poverty alleviation;

3) Reduce disparities and coordinated development between rural and urban areas as well as between regions to ensure that the impoverished enter the moderate prosperous society; and

4) Socialism with Chinese characteristics should display stronger vitality to adapt to the broader societal needs of quality of life, fairness, justice and security, as well as improved living conditions [44].

\section{2) Socio-economic development}

The Decision on Education System Reform of 1985 [36] indicated that the reform of the education system has created opportunities for the development of social and productive forces to improve socialism, prosperity and ideology of China. The main objective of education during the 1990s was oriented towards modernization, the world, the future, and the development of China's multifaceted economic and 
social needs. In addition, the strategic goal of higher education development was to establish a comprehensive structure and levels of education with a reasonable education system equal to China's economic strength before the end of the century. The policy stated that the structure of higher education should be adjusted and reformed according to the needs of economic construction and social development to ensure scientific and technological progress. All talents should have ideals, morals, culture and discipline, appreciation of the socialist motherland and the cause of socialism, and have dedication to strive for prosperity of the country and its people. During China's opening-up and being challenged by the global technological revolution, invigorating the economy and the comprehensive reform of the economic system became evident. From an education perspective, numerous challenges existed including the malpractice of the education system, a limited professional spectrum owing to the disparities in economic and social development, and a stagnant contemporary scientific culture. Moreover, government investment in education was subject to the level of economic development and the development of modern productive society which symbolized a modern civilization. However, owing to the vast size of the country, unbalanced economic and social development existed. The central government believed that under the new economic and education system, all regions will have the opportunity to realize their economic and cultural potential and accelerate education development. The economic and cultural development imbalances between cities, counties and provinces were recognized. Developed areas were encouraged to assist less developed areas in achieving economic, cultural and social development.

\section{3) Progressing strengths}

As far back as 1985 [36], the importance of improving the economic and social cultivation of China was highlighted to develop the socio-economic needs of the country. In this regard, education and specifically higher education played a key role. During the 1980s, the general education levels in China were relatively low and did not match the challenges presented by modernization. It was therefore decided that in the future education should be directed towards modernization [38]. To achieve modernization, importance was placed on lower-level governance, improving institutions and mechanisms through which leadership, ethnic and religious affairs were managed, as well as public awareness of authority and the influence of law in the society. Thus, by building progressive strength, the alleviation of poverty and employment creation was emphasized. In this respect, the social security system had to be improved for both urban and rural residents, providing government-subsidized housing and ensuring that basic needs of the society are met [43]. Furthermore, efforts to advance society has been accelerated. A program to protect society against moral corruption was also initiated. It was again emphasized by the Implementation Measures for Promoting World Class Universities and First-Class Discipline Construction that China's economic and social needs should be strengthened. To pursue national rejuvenation the strengthening of education was of central

\section{importance.}

\section{B. Promote a Socialist Market Economy}

To contribute to the purpose of promoting a socialist market economy, attention should be given to two critical building blocks namely, socialism and international competition:

\section{1) Promoting socialist consultative democracy}

The ordained model by which Chinese citizens live their daily lives is rooted in socialism. It is the responsibility of higher education to ensure that scholars at all levels, including ideological and political staff, administrative and logistical staff, students, as well as including all other staff, are prepared and adhere to the guidelines of socialism with Chinese characteristics [36-[44]. This preparation should include love of the motherland and the cause of socialism in an effort to build a prosperous, democratic and modern socialist country [36]. The Party Committees are particularly tasked to focus on party building and strengthening the ideological and political work in higher education [36], [38]. By the mid-1990s, a decision was made to establish a new educational system adapted for the socialist market economy and political system, and to reform the scientific and technological system [37]. This initiative required strengthening the advancement of education of party members as well as education in the construction of grass-roots Party Committees. To facilitate proper implementation, the ideological and political work of higher education had to be cascaded down into all academic departments, associations and into the broader higher education network. At the core of implementation is the responsibility by both teachers and students to study Marxism-Leninism, Mao Zedong thoughts, the Theory of Three Represents, and in particular the theory of building socialism with Chinese characteristics by Deng Xiaoping [37], [39], [40], and the Scientific Outlook on Development [43]. The basic outline of education had to focus on patriotism, collectivism and socialism, together with the emancipation of the mind and all-round development based upon the cultivation and development of three characteristics namely, virtue, wisdom and body [37]. In general, higher education is guided by the leadership of the Communist Party, which is regarded as the highest political leadership in China. As such the model was labelled by the leader of the Communist Party as a "Socialist consultative democracy" [43] in which party leadership will ensure that the country is run by the people, whereas the people is regarded as an essential feature of socialist democracy, and law-based governance should guide the people in governing the country.

\section{2) Participation in international competition}

The emphasis of the 1985 Decision on Education System Reform policy on the internationalisation of higher education was to benefit domestic educational undertakings by focusing on comprehending positive and negative experiences and strengthening external exchanges based upon the achievements of the contemporary world [36]. By 1999, the role of higher education was even more tightly focused when the emphasis shifted to the level of education development, science and technology, and knowledge 
innovation as drivers of international competition. These drivers raised the demand for the modernization of higher education, starting with the strengthening of comprehensive higher education and the international competitiveness of higher education. This resulted in a rise in the number of world-class universities and first-class disciplines that have entered the world's forefront and have a strong international influence [39], [40], [43], [44].

By 2017, the socialist drive focused on the construction of an advanced socialist culture, enhancement of cultural confidence, spreading of an international socialist culture, a strong cultural innovation ability, and providing leading social progress [43]. During the last two decades, the priorities were further refined as China moved to the center stage of influence by including to [43], [44]:

1) Make greater contributions to mankind and ensuring global development and ecological security;

2) Build a beautiful China able to create working and living environments;

3) Contribute to global development and the upholding of international order;

4) Support traditional industries in upgrading and accelerating modern service industries to elevate to international standards and move Chinese industries to the medium-high end of the global value chain, whilst fostering a number of world-class advanced manufacturing clusters;

5) Reform state-owned enterprises and develop mixed-ownership models to turn Chinese enterprises into world-class globally competitive firms;

6) Strengthen the international economic co-operation through globally-oriented networks of trade, investment and financing, production and services, and excessive contacts with overseas Chinese nationals and returned nationals;

7) Increase assistance to other developing countries, especially the least developed countries, to reduce the North-South development gap;

8) Support multilateral trade regimes, facilitate the establishment of free trade zones and building of an open world economy; and

9) Participate in reforming and developing the global governance system.

\section{Talent Management}

The findings reveal that the evolving higher education system in China is faced with an ambitious task of improving and unleashing millions of human talents to the labor market that are fit-for-purpose over a myriad of economic sectors, professions and disciplines based upon specific fundamental criteria:

1) A proper level and knowledge of modern science, technology, and management should be developed;

2) An appropriate skill-set should be acquired; and

3) A socialist culture should be adopted.

This ambition is set against an acute shortage of students that are sufficiently equipped for innovative, practical and versatile professions. Consequently, China wants to move from being a country with large scale human resources to a country rich in human resources. For this reason, the government regards human resources as the foremost asset of the country.

Hence, the stated development trajectory of China is based upon the principle of putting people first "through human resource development." The expectation is that higher education should provide millions of talents to the workforce, with a large number of talents at the top-level of innovation. All-round as well as individual characteristics also need to be improved. In particular, the focus should be on the mediumand long-term forecast of talent demand, cultivating younger generations and building an extensive, properly structured and high quality talent cohort, expanding continuing education; and building a lifelong learning and training system for the broader society [39], [40].

\section{CONCLUSION}

The findings reveal that nation-building in China is guided by three clear macro directives: a socialist market economy, a global influence ambition, and talent management. In this, higher education plays a core role in assuring its realization and conditioning through achievements in training, research, and service to the nation. This should specifically occur in the fields of citizen education, science and technology, talent management, and innovation. In this sense, nation-building presents a complex, accelerating, and dynamic long-term process and challenge that is closely linked to modernization. Congruently, the findings reveal a progressive and liberating approach in how nation-building should be approached in content as well as in ambition requiring and building on the freedom of the mind under the guidance of the strategic direction of a state-led government. Such a condition favors the whole ethos on which higher education could thrive proviso even further strengthening of international co-operation, mobilization of social support, ability to compete at the frontier of knowledge and the assurance of quality exist.

The building of a socialist market economy will be strengthened and powered by the establishment of a socialist consultative democracy and through participation in international competition and be based on clear building blocks to advance socialism including application of scientific principles, emancipation of the mind to innovate, all round development, patriotism and confidence and the 10 building blocks provided to enhance international competition. Such a framework provides a common framework to higher education on how to approach the institutionalization of a socialist market economy into the functioning and scholarship approaches of institutions. This greater convergence gives greater clarity on the roles to be played by higher education whilst allowing for the unleashing of innovative scholarship. If higher education can succeed to socialize scholars into these norms, it should inculcate global influence in higher education and set new norms for global higher education excellence. In its contribution to nation-building, it is expected that higher education at minimum should contribute to produce a capable workforce for a modern global and local era whilst pursuing socialism with Chinese characteristics.

The study revealed that the global influence ambition is 
considered to be dependent on three powers namely, the building of strategic strength, socio-economic development and progressive strength. Higher education is tasked specifically to help build the national quality of people, broaden the professional setting of the nation, enroll large numbers of scholars, expose scholars to modern information, cultivate their innovativeness and try to build world-class and high-level universities to enhance the strategic strengths of the country. To support socio-economic development, universities should focus on the principles of modernization and the extension of their reach to serve the nation. Adopting progressive strength requires from higher education to have a future orientation and to continuously strengthen education in all spheres. Such emphasis signals a need for greater autonomous planning from state planning agencies, but still tied to the national ambition directions of the state-led government.

It follows that talent management in China is based upon the principle of "fit-for-purpose" in a modern local and global market of the workforce, whilst pursuing the cause of socialism. For higher education the implications are to ensure improvements in talent as it relates to quality in production, the practicality of education and the rejuvenation of the country as a whole. Furthermore, higher education is required to provide appropriate skill-sets rooted in modern scientific knowledge, technology and management knowledge. For this higher education requires progressive predictive and machine learning capabilities to provide strategic direction of global and local changes in the making.

\section{CONFLICT OF INTEREST}

The authors declare that they have no competing interests in relation to this manuscript and that there are no financial or financially competing interests to declare.

\section{AUTHOR CONTRIBUtions}

L. Steynberg and J. P. Grundling conceived the presented idea, developed the theory, wrote the manuscript, performed the analytic calculations and interpreted the findings with inputs from B. Liu and Y. Li. L. Steynberg ensured compliance with the technical requirements. Y. Li verified the analytical methods and supervised the findings of the research. B. Liu supervised the work. All authors provided critical feedback, discussed the findings and contributed to the final manuscript.

\section{REFERENCES}

[1] X. Yan, "The rise of China in Chinese eyes," J Contemp China, vol. 10, no. 26, pp. 33-39, 2001.

[2] J. P. Xi, (2014). Speech at UNESCO Headquarters, Paris. [Online]. Available: http://www.china.org.cn/chinese/2014-04/01/content_31964496.htm

[3] J. Zeng and S. Breslin, "China's 'new type of great power relations': A G2 with Chinese characteristics?" Int Aff, vol. 92, no. 4, pp. 773-794, 2016.

[4] J. Li, "Educational policy development in China for the 21st century: Rationality and challenges in a globalizing age," Chinese Educ Soc, vol. 50, no. 3, pp. 133-141, 2017.

[5] H. De Wit, Internationalization of Higher Education in the United States and Europe: A Historical Comparative and Conceptual Analysis, Westport: Greenwood Publishing Group, 2002.

[6] A. Luijten-Lub, M. Wende, and J. Huisman, "On cooperation and competition: A comparative analysis of national policies of internationalisation of higher education in seven European countries," $J$ Studies in Int Educ, vol. 9, no. 2, pp. 147-163, 2005.

[7] F. Maringe, "Leading learning: Enhancing the learning experience of university students through anxiety auditing," Educ, Knowl, and Econ, vol. 4, 15-31, 2010.

[8] F. Marmolejo. (2010). Internationalization of higher education: The good, the bad, and the unexpected. Chr Higher Educ. [Online]. Available:

http://chronicle.com/blogs/worldwise/internationalization-of-higher-e ducation-the-good-the-bad-and-the-unexpected/27512

[9] L. Matei and J. Iwinska, "National strategies and practices in internationalization of higher education: Lessons from a cross-country comparison," Higher Education Reforms in Romania: Between the Bologna Process and National Challenges, Dordrecht, The Netherlands: Springer, 2015, pp. 205-226.

[10] L. Feng and G. Shi, "Local university research on local internationalization," Int J Info and Educ Tech, vol. 8, no. 3, pp. 245-248, 2018.

[11] A. B. Kipnis, "Constructing commonality: Standardization and modernization in Chinese nation building." J Asian Stud, vol. 71, no. 3, pp. 731-755, 2012

[12] L. Wing-Wang, "Globalisation, national identity, and citizenship education: China's search for modernization and a modern Chinese citizenry," Front. Educ. China, vol. 8, no. 4, pp. 596-627, 2013.

[13] R. M. Helms and L. E. Rumbley, "Global: National policies for internationalization - Do they work?," Higher Education Internationalization: Insights from Key Global Publications, Rotterdam, The Netherlands: Sense Publishers, 2017, pp. 131-134.

[14] K. MacGregor. (2014). International HE associations call for global equity. University World News. [Online]. Available: http://www.universityworldnews.com/article.php?story=20140118132 339578

[15] F. Maringa, N. Foskett, and S. Woodfield, "Emerging internationalisation models in an uneven terrain: Findings from a global survey," Compare, vol. 43, no. 1, pp. 9-36, 2015.

[16] J. Tahira and M. A. Khan, "Internationalization of higher education Potential benefits and costs," Int J Eval Res Educ, vol. 4, no 4, pp. 196-199, 2015.

[17] E. Buckner, "The internationalization of higher education: National interpretations of a global model," Comp Educ Rev, vol. 63, no. 3, pp. 315-336, 2019.

[18] V. M. Hudson, "Foreign policy analysis: Actor-specific theory and the ground of international relations," Frgn Pol Anal, vol. 1, pp. 1-30, 2005.

[19] R. C. Snyder, H. W. Bruck, and B. Sapin, Decision-Making as an Approach to the Study of International Politics, Foreign Policy Analysis Project Series No. 3, Princeton, NJ: Princeton University Press, 1954.

[20] Z. Wang, "National humiliation, history education, and the politics of historical memory: Patriotic education campaign in China," Int Stud $Q$, vol. 52, pp. 783-806, 2008.

[21] K. J. Kennedy, "Young citizens in Hong Kong: Obedient, active and patriotic?" Soc Psychol Educ, vol. 13, pp. 111-127, 2010.

[22] R. Andrews and A. Mycock, "Citizenship education in the UK: Devolution, diversity and divergence," Cit Teach Learn, vol. 3, no. 1, pp. 73-88, 2007.

[23] T. Scott and J. J. Cogan, "Democracy at a crossroads: Political tensions concerning educating for citizenship in the United States," Citizenship Curriculum in Asia and the Pacific. CERC Studies in Comparative Education, vol. 22, Dordrecht, The Netherlands, 2008.

[24] L. Hoffman, "Autonomous choices and patriotic professionalism on governmentality in late-socialist China," Econ Soc, vol. 35, no. 4, pp 550-570, 2006.

[25] M. D. Gall, W. R. Borg, and J. P. Gall, Educational Research: An Introduction, $6^{\text {th }}$ ed. New York: Longman, 1996.

[26] F. Rizvi and B. Lingard, Globalizing Educational Policy, London, U.K.: Routledge, 2010.

[27] A. R. Cornelius, "Intentional internationalization of higher education: A strategic institutional response to globalization," $\mathrm{PhD}$. dissertation, Dept. Leadership, Technology and Human Dev., Georgia Southern Univ., Statesboro, Georgia, 2012.

[28] G.T. Owen, "Qualitative methods in higher education policy analysis: Using interviews and document analysis," Qual Rep, vol. 19, no. 26, pp. 1-19, 2014.

[29] S. Valimoghadam, N. Kamali, and M. MojtabaZadeh, "Role of government in internationalization of higher education in universities of medical sciences of the country: A qualitative research," Med Educ Dev, vol. 12, no. 33, pp. 43-55, 2019. 
[30] M. L. Smith, "Multiple methodology in education research," Handbook of Complementary Methods in Education Research, Mahwah, NJ: Lawrence Erlbaum Associates, 2006, pp. 457-475.

[31] N. K. Denzin and Y. S. Lincoln, "Introduction: The discipline and practice of qualitative research," in Handbook of Qualitative Research, $3^{\text {rd }}$ ed. N. K. Denzin, and Y. S. Lincoln, Eds. Thousand Oaks, Sage, 2005, pp. 1-32.

[32] S. B. Merriam, Qualitative Research and Case Study Applications in Education, San Francisco: Jossey-Bass, 1998.

[33] B. Berelson, "Content analysis," in Handbook of Social Psychology, vol. 1, G. Lindzey, Ed. Reading, MA: Addison-Wesley, 1954.

[34] C. Glesne, Becoming a Qualitative Researcher, $3^{\text {rd }}$ ed. Boston: Pearson, 2006.

[35] S. B. Merriam, Qualitative Research in Practice: Examples for Discussion and Analysis, San Francisco: Jossey-Bass, 2002.

[36] Chinese Communist Party Central Committee (CCP CC), Decision on Educational System Reform, Beijing: Foreign Language Press, 1985.

[37] Chinese Communist Party Central Committee (CCP CC) and State Council, Outline for Reform and Development of Education in China, Beijing: People's Press, 1993.

[38] Ministry of Education of the People's Republic of China (MOE) and State Council, Action Plan for Revitalization of Education in the Twenty-First Century, Beijing: Ministry of Education, 1999.

[39] Ministry of Education of the People's Republic of China (MOE), 2003-2007 Action Plan for Revitalization of Education, Beijing: Ministry of Education, 2004.

[40] J. Zhou. (2004). The full implementation of the 2003-2007 action plan for invigorating education. [Online]. Available: http://www.edu.cn/20040324/3102182.shtml

[41] 17th Communist Party of China National Congress. (2010). Outline of China's National Plan for Medium- and Long-Term Education Reform and Development (2010-2020). [Online]. Available: http://uil.unesco.org/fileadmin/keydocuments/LifelongLearning/en/ch ina-2010-abstract-11l-strategy.pdf

[42] People's Daily Online. (2017). China to Develop 42 World-Class Universities. [Online]. Available: http://en.people.cn/n3/2017/0921/c90000-9272101.html

[43] Chinese Government. (2017). Implementation Measures for Promoting World Class Universities and First-Class Discipline Construction. [Online]. http://www.gov.cn/xinwen/2017-01/27/content_5163903.htm\#1

[44] J, Xi, Secure a Decisive Victory in Building a Moderately Prosperous Society in all Respects and Strive for the Great Success of Socialism with Chinese Characteristics for a New Era, Beijing: Chinese Communist Party Central Committee, 2017.

[45] R.K. Yin, Case Study Research: Design and Methods, $5^{\text {th }}$ ed. Thousand Oaks, CA: Sage Publication, 2013.

[46] L. Prior. (2003). Using documents in social research [21 paragraphs]. Forum: Qual Soc Res. [Online]. Available: http://nbnresolving.de/urn:nbn:de:0114-fqs0401151

[47] P. Bazeley, Qualitative Data Analysis with NVivo, $2^{\text {nd }}$ ed. Thousand Oaks, CA: Sage Publication, 2007.

[48] A. L. Strauss and J. Corbin, Basics of Qualitative Research: Grounded Theory Procedures and Techniques, $2^{\text {nd }}$ ed. Thousand Oaks: Sage, 1998.

[49] B. G. Glaser and A. L. Strauss, The Discovery of Grounded Theory, New York: Aldine, 1967.

[50] K. Punch, Introduction to Social Research: Quantitative and Qualitative Approaches, London: Sage Publishers, 1998.

[51] U. Kuckartz, Qualitative Text Analysis: A Guide to Methods, Practice and Using Software, London: Sage Publications, 2014.

Copyright $\odot 2020$ by the authors. This is an open access article distributed under the Creative Commons Attribution License which permits unrestricted use, distribution, and reproduction in any medium, provided the original work is properly cited (CC BY 4.0).

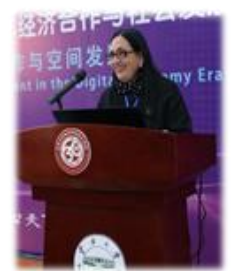

Lizl Steynberg was born in Kroonstad, Free State in South Africa in 1971. She started her post secondary career at North West University (NWU) in Potchefstroom, South Africa where she obtained her B.A degree in 1993, B.A. (Hon) degree in 1995 and M.A degree with distinction in 1998.

She has started her academic degree at NWU in 1994 as a researcher and in 2001 she joined Tshwane University of Technology (TUT) in Pretoria, South Africa. In 2017, as part of the Memorandum of Understanding between TUT and Hebei University of Technology (HEBUT) in Tianjin, People's Republic of China, she was nominated for the staff exchange programme between the two universities and commenced with her $\mathrm{PhD}$ degree in Technology Economy and Management in the School of Economics and Management at HEBUT. Over her teaching career she taught 14 different undergraduate and 3 different postgraduate courses. Besides her local teaching commitments, she has supervised over 12 postgraduate students, presented more than 40 conference papers, published 14 academic articles, contribute to 5 academic books and continues to enjoy the priveleges of research writing and lecturing at a national and international level. Her main areas of interest are internationalisation of higher education and research methodology. She has collaborated actively with researchers in several other disciplines of entrepreneurship and small business management.

Ms. Steynberg is also a senior researcher at the South Africa-China Transport Co-Opertion Center (SACTCC), Executive Board Member of the Southern Africa-China Science, Engineering and Technology, and Education Association (SETEA), member of the Centre for Local Economic Development (CENLED) at the University of Johannesburg, South Africa, and member of Pascal Observatory Africa. During her academic career she has received the TUT Vice Chancellor Achiecement Award in 2003; research awards from TUT in 2003, 2004, 2005, 2006, 2007, 2008 respectively; and Outstanding Teaching Award from TUT in 2015. Furthermore, she also has received the Best Paper Award at the $2^{\text {nd }}$ Annual Conference on Mangement in 2004 and The Best Track Paper Award for the $1^{\text {st }}$ Annual Conference of the Faculty of Management Sciences at the University of Johannesburg in 2004 as well as the $18^{\text {th }}$ European Conference on Research Methodology for Business and Management Studies in 2019.

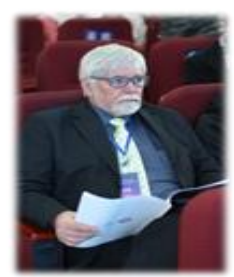

Jan P. Grundling was born in Kirkwood, Western Cape, South Africa in 1956. He obtained is B.Com degree in industrial psychology, 1979 from Stellenbosch University, Western Cape, South Africa. In 1982 he completed his B.Com (Hon) and in 1986 his M.Com degree in industrial psychology from the University of South Africa, Pretoria, Gauteng, South Africa. He obtained his PhD. degree in organisational leadership entitled Implicit relational leadership determinants of late adolescent subjective well-being in Gauteng from Tshwane University of Technology, Pretoria, Gauteng, South Africa in 2017.

In 1980 he started his career at the South African Defence Force (SADF), and was appointed as the Head of the Department of Industrial Psychology at the Military Academy in Saldanha, Western Cape, South Africa. In 1987 he was promoted to Senior Office at Military Intelligence in Pretoria, Gauteng, South Africa. From 1988 to 1994 het joined the Armament Corporation of South Africa as Training Manager in Pretoria, Gauteng, South Africa and in 2001 he joined Tshwane University of Technology (TUT), Pretoria, Gauteng, South Africa. During his career at TUT, he was the Director of the Centre of Entrepreneurship (2001-2012), Organisation Director for the Joint African Masters on Comparative Local Development (2003-2012), and he is currently a researcher and senior lecturer in the Faculty of Management Sciences at TUT, Pretoria, Gauteng, South Africa, as well as a research fellow at Chang'an University, Xi'an, Shaanxi Province, People's Republic of China. He has published more than 110 conference papers and 42 journal articles in his research field, hosted and participated in more than 20 national and university level scientific research projects in South Africa and abroad Additionally, he has published more than 10 academic books, served as reviewers of more than 10 South African and international academic journals, supervised more than 40 masters and PhD students. His main research field include linear programming, optimisation and control, industrial statistics and entrepreneurship.

Dr. Grundling is an Associate of the African Pascal International Observatory Network in Africa, Advisor for the South Africa-China Transport Co-Operativee Center (SACTCC), Executive Deputy President for the Southern Africa-China Science, Engineering and Technology, and Education Association (SETEA), Member of the Human Relations Journal Reviewers Club, Member of the Pretoria Chamber of Commerce and Industry's Workgroup on Small and Medium Sized Enterprise Development, and reviewer fo the South African National Research Fund (NRF). He received more than 11 awards for his contribution to industry and academe.

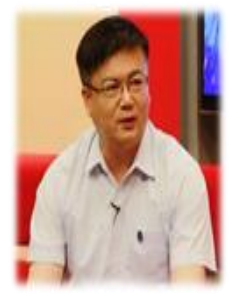

Bing Liu was born in the People's Republic of China on 19 December 1968. He obtained a bachelor degree in management from Hebei University of Technology, Tianjin, People's Republic of China in 1990, master Degree in management engineering from Tianjin University, Tianjin, People's Republic of China in 1997 and $\mathrm{PhD}$ in management science and Engineering from the same institution in 2000. His main research interest is in the field of human resource management 
and information system development, as well as marketing research management.

He commenced his professional academic career in 1994 at the School of Management at Hebei University of Technology in Tianjin, People's Republic of China. With an academic career spanning over 25 years, he is actively involved in university management, teaching, research and $\mathrm{PhD}$ supervision. As a celebrated researcher he has acted as project leader for more than 10 research projects awarded by the Education Bureau of Hebei Province, Hebei Planning Office of Philosophy and Social Science, Soft Science of Hebei Province, Doctor Funds of the Educational Bureau of Hebei Province, and Natural Science Funds of Hebei Province. As an expert in his field, Prof. Liu has published more than 100 scholarly works during his academic career.

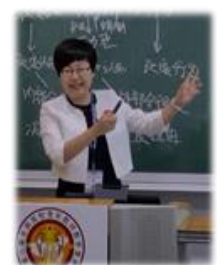

Li Yuan was born on 1 February 1983 in Tianjin, People's Republic of China. She obtained her PhD as a joint programme between the University of New South Wales, Syndey, Australia and Hebei University of Technology, Tianjin, People's Republic of China in 2012 that was fully sponsored by the China Sponsorship Council Postgraduate Program.

She started her research and teaching career in the School of Economics and Management, Hebei University of Technology, Tianjin, People's Republic of China. Currently she is an Associate Professor and besides her research and supervising duties, she is teaching courses in Organizational Behavior, Management Communication, Compensation Management, IT Performance and Research Methodology on pre- and postgraduate levels. As a respected academic, she has published more thn 10 A-ranked articles in national and international journals, as well as presented various conference papers of which she won two best paper awards for $A$ Typology and Hierarchical Framework of Technology Use in Digital Natives' Learning and Students' Motivations for Using Contemprary Technologies in Learning: A Structural Approach. Her current research interests are positive organization behavior, team creative behavior and ICT adoption behavior.

Ass Prof. Li has received various honors for her contribution to academia including Winner of the $2^{\text {nd }}$ Prize for the National Higher Education Teaching Competition of Colleage Young Teachers in China in 2016, Winner of the Provincial Labor Medal in Tianjin, China, 2015, Winner of the $1^{\text {st }}$ Prize for the Provincial Higher Education Teaching Competition of College Young Teachers in Tianjin, China in 2014, Winner of the Association of Information Systems (AIS) Awards for Best Conference Paper in IS Education in 2011, and Winner of the International Academy for Information Management (IAIM) Awards for Best Paper of the AIS Special Research in Education (SIG-ED) Conference in 2011. She has also participated and managed more than 10 research projects from the National Natural Science Foundation of China, Social Science Foundation of Hebei Province, Hebei Educational Reform Grant of Hebei Province, Online Education Research Grant of Ministry of Education of the People's Republic of China, China Postdoctoral Science Foundation, National Natural Science Foundation of China, Natural Science Foundation of Hebei Province, and National Soft Science Research Plan of China. 